\title{
Alignment of Teacher-Developed Curricula and National Standards in Qatar's National Education Reform
}

\author{
Ramzi Nasser ${ }^{1,2}$, Eman Zaki ${ }^{2}$, Nancy Allen², Badria Al Mula², Fatma Al Mutawaha ${ }^{2}$, \\ Hessa Al Bin $\mathrm{Ali}^{2} \&$ Tricia Kerr ${ }^{2}$ \\ ${ }^{1}$ Supreme Education Council, Doha, Qatar \\ ${ }^{2}$ Qatar University, Doha, Qatar \\ Correspondence: Ramzi Nasser, Supreme Education Council, Doha, Qatar. Tel: 974-6605-7952. E-mail: \\ ramzinaimnasser@hotmail.com
}

Received: January 26, 2014 Accepted: May 9, 2014 Online Published: September 22, 2014

doi:10.5539/ies.v7n10p14 URL: http://dx.doi.org/10.5539/ies.v7n10p14

\begin{abstract}
This study investigated the degree to which teacher developed curriculum was aligned with the national standards in Qatar. Three sources of data included teacher response to a questionnaire, teacher interviews and expert rating of the alignment of teacher-developed materials with curriculum standards. A survey and interview questions measured teacher roles and methods in developing the curriculum. Expert ratings measured the degree of alignment of objectives, activities, lesson elements and assessment with the standards. Results indicated that the objectives of units and lessons in each of the four subject areas Arabic, English, mathematics and science, closely aligned with tasks and artifacts. These elements of instruction also showed satisfactory alignment in terms of content, scope, developmental level, and cognitive level with the standards. Assessments, however, showed a serious lack of alignment with the standards in terms of scope and developmental level, especially in the cognitive level alignments in each of the four subject areas. Teachers also reported that developing curriculum, in addition to other school related activities, has generally overloaded teachers. This study has significance in terms of professional development needs and policy decisions in Qatar and similar contexts, especially those engaged in education reform.
\end{abstract}

Keywords: curriculum, curriculum standards, alignment, assessment, Qatar, and educational reform

\section{Introduction}

In 2001, the government of Qatar embarked on an educational reform and initiative intended to meet the country's changing economic and social needs (Brewer et al., 2007, p. iii). This decision arose from the understanding that oil and gas, which currently drive Qatar's economy, are finite, and that there is need to invite and invest in a knowledge-based economy for Qatar's long-term sustainable evolution as a worldly nation (Al-Sulayti, 1999). Such a goal requires raising the achievement level of students in schools. The government approached RAND Corporation research organization and requested a comprehensive examination of Qatar's K-12 education system. RAND was given the task of investigating the existing educational system and providing recommendations and options for building "a world-class system that would meet the country's changing needs" (Brewer et al., 2007, p. xvii). As a result, Qatar initiated a systematic school reform strategy, known as Education for a New Era (Brewer et al., 2007).

Education for New Era was designed to catapult Qatar Education into a world-class system that would drastically change the K-12 landscape. The vision was to create high-quality schools that would develop human capacity through providing extensive teacher professional development coupled with innovative educational and social policies (Brewer et al., 2007). Several changes quickly took place. In November 2002, the Supreme Education Council (SEC) was established to replace the Ministry of Education. The SEC provided direction for the nation's educational policy. The State of Qatar decided to gradually transform the centralized school system that was traditionally regulated by the Ministry of Education (MOE) to a decentralized government-funded-semi-autonomous independent school system known as Independent Schools (charter-like schools) (Zellman et al., 2009).

Currently, all schools in Qatar, whether private or independent, fall under the Supreme Education Council 
(previously Ministry of Education), and all previously government-run schools have been transformed into government-funded Independent Schools. Qatar's educational reform has dramatically changed the landscape of the educational system, specifically in the transformation of the educational system into a standardized based system (Brewer et al., 2007).

The Supreme Education Council in 2005 published curriculum standards in Arabic, English, mathematics, and science, then followed by Arabic in subsequent years; Islamic Studies and social studies subject standards followed. Annual standardized assessment tests were also developed and administered to all grade levels K-12. The 2008 test results showed a low proportion of students meeting curriculum standards benchmark level-about $10 \%$ of students in English, about 5\% or less of students in Arabic, and close to $0 \%$ of the students in mathematics and science who reached the standards.

As researchers and educators in Qatar, we were aware of the challenges at hand. Teachers were expected to develop the curriculum, aligned with standards. Anecdotal data indicated that teachers were experiencing frustration in developing and using such curriculum. The question emerged as to whether one of the challenges faced by teachers might be a lack of alignment between the curriculum and the standards.

\subsection{Standards-Based Education}

Standard based education has come about as a result of a movement toward performance-based outcomes and school accountability. This movement began in the early 1980's in the United States (US) following several influential, and alarming, reports on school quality (National Commission on Excellence in Education, 1983) and culminating with the extensive policies of the No Child Left Behind legislation (US Department of Education, 2001). In many US States, an accountability system has been put in place where a Consolidated State Application Accountability Workbook is submitted to the Department of Education by the State's Office of Education. There are achievement standards in all subjects at all grade levels that have been aligned with the individual state documents corresponding to grade-level content standards. Many of the US States have assessments that are generally not aligned to achievement standards (Department of Education, n.d.). Other states have used national assessments to account for the standards. This was followed by a number of international and global initiatives advancing standard based outcomes (National Commission on Excellence in Education, US Department of Education, n.d.). The initiative went further to align individual state standards with school based assessments, later manifested in US national and international school system standard-based alignments (Contino, 2013).

Today's standard-based reform operates as the key school reform principle, especially in an international market-based reform model. The basic principle of standards-based reform is a standard-based teaching-learning curriculum and a standard based assessment (Sahlberg, 2011). The alignment of standards and assessment is key to today's reform effort in which assessment serves as a measure of success of the reform effort. Mandatory school assessments underline what teachers should be teaching and what students should be learning.

Currently all Independent Schools in Qatar are required to use the Qatar National Curriculum Standards as the basis for curriculum and instruction. No published research was found that has evaluated the development, implementation and outcomes of the standards in the context of Qatar. Because the national standardized assessment exam was aligned with standards and students were not succeeding on these exams, we wanted to investigate whether teacher-developed curriculum was aligned with targeted students outcomes as identified in the standards.

\subsection{Curriculum Alignment}

Herman and Webb (2007) claimed that for an educational system to work, specific and major elements of the system must be aligned. They stressed that three main alignments must be in place for the educational system to function: alignment of assessment with the curriculum standards, alignment of teaching and learning with the curriculum standards and alignment of assessment to the teaching and learning. Alignment thus provides a sense of how well teachers and students are doing in their teaching and learning respectively. Research studies such as Baker's (2004) found low performing schools conversion into a standard-based system, significantly increased student achievement through strong curriculum alignment and standards-based instruction.

Research has shown that curriculum standards alone do not produce higher academic achievement; however, research consistently supports student learning through a process of assessment of what they are taught (Porter, 2002; Rothman, Slattery, Vranek, \& Resnick, 2002). Alignment between assessment and curriculum standards is a prerequisite to the success of student educational outcomes and overall educational improvement (Webb, 2007). 
A number of alignment strategies have been reviewed by Davis-Becker and Buckendahl (2013). They cite Webb's (1999) alignment strategy that evaluates assessment items aligned with content standards. A second strategy is a procedure where expert judges use a matrix with content on one dimension crossed by pre-established cognitive demand list. This matrix can be multidimensional by crossing other dimensions of content by assessment; or by curricula standards or by cognitive complexity i.e., the cognitive level or taxonomy required of students thinking by content standards. In Qatar, the alignment among curriculum standards, planned curriculum, assessment and the teaching of the curriculum are now validated through an international achievement test, based on international standards. The notion that when comparisons are made to international content standards, the educational system moves closer to a global and credible educational system (Baker, 2004).

Alignment is a complex and systematic process requiring school wide effort. B. Gannod, G. Gannod, and Henderson (2005) suggested several steps be taken for alignment: first, determine what the desired curriculum should look like; second, compare the desired curriculum with existing curriculum and determine the "gaps" between the two; and third, suggest changes that could be made to move the curriculum from its current state to the desired state. Nunan (2001) cautioned that curriculum evaluators should distinguish among the planned curriculum, which includes everything done prior to the actual instruction, the implemented curriculum (the instruction) and the realized curriculum (what students actually acquire from the instruction). All three facets of curriculum standards-curriculum, instruction and assessment-are essential for students to achieve academically.

Several authors have modified Webb's procedures to measure alignment (Herman, Webb, \& Zuniga, 2002; Bhola, Impara, \& Buckendahl, 2003; Plake, Buckendahl, \& Impara, 2001 (cited in Fulmer, 2011); Wixson, Fisk, Dutro, \& McDaniel, 2002, (cited in Fulmer, 2011)), exploring best strategies to assess the appropriateness of the curriculum and assessment. These studies suggest that not one way is perceived to be a "best" or "correct" alignment method.

The present study investigated teacher alignment of teacher-developed curriculum with educational elements and curriculum standards. We used an alignment methodology through a set of common sense expectations. The focus of this research was to analyze teacher planned curriculum and how such curriculum was aligned with the different aspects of instructional practices. The driving research question of this study addressed whether the teacher-developed curriculum in selected schools was aligned with the curriculum standards.

\subsection{Research Questions}

The specific research questions guiding the study were:

(1) Do unit and lesson objectives align with curriculum standards in content and grade level?

(2) Does the content reflect the objectives and curriculum standards?

(3) Are the classroom activities aligned with the objectives and with the national curriculum standards?

(4) Are the assessment practices aligned with curriculum objectives and activities and with the national curriculum standards?

(5) What are the difficulties teachers face in aligning the curriculum to the standards?

\section{Methodology}

This study used multiple sources of data (triangulation) to answer the research questions (Lincoln \& Guba, 1985). First, teacher perceptions were elicited through a scale that rated how well they aligned their work to the curriculum standards. Second, interview questions assessed teacher perceived difficulty in the implementation of the curriculum. Third, specialist in each cognate area-Arabic, English, mathematics and science-assessed the number and grouping of standards, and whether there was a degree of alignment of teacher-developed objectives, learning activities, assessments, the written curriculum standards and assessed the degree of alignment in the cognitive domain (Bloom, 1956) between intended learning as expressed in the objectives, activities, assessments and the curriculum standards.

\subsection{Sample}

In 2004, the first cohort school was transformed into an Independent School in Qatar. As of 2010/2011 public schools have been all transformed into Independent Schools. We selected nine of the first 13 cohort primary schools that were transformed into Independent Schools. Since this study was carried out in 2012/2013 academic year, the interest was in schools that have had the longest experience dealing with the standards and assessments reflecting those standards. The first cohort of schools which implemented the reform was in 2004. Thus the criteria was to select the first schools which were transformed into Independent Schools and the first to 
implement the reform principles i.e., curriculum standards. These schools were more likely to demonstrate the changes targeted by the reform since these schools would have had more time to do so. From these schools teachers were approached through the school administration and they were explained the nature of the study. Teachers were asked to volunteer for the study. Those who accepted were teachers of Arabic, English, mathematics and science (as these were the first four subjects that the curriculum standards were developed). As a result 58 volunteer teachers came from nine schools, they responded to the questionnaire, which came to approximately $33 \%$ of the total population of teachers in the nine schools. In addition to the questionnaire, 28 teachers of the 58 teachers volunteered for the interviews reporting $16 \%$ of all the teachers in the nine schools.

\subsection{Instruments}

\subsubsection{Teacher Questionnaire}

A 30-item questionnaire was developed by the authors and validated by obtaining feedback from faculty of education in the only national university. It consisted of demographic information and 30 questions. The items were rated on a 4-point Likert-type scale from 1="never," 2="sometimes," $3=$ "often," and 4="always;" and three open-ended questions. The questionnaire addressed whether teachers designed their own lesson plans, assessments, and/or curriculum units. Questions also asked about teacher knowledge of the standards, type of resources and the help they received to develop lessons, whether they mapped their curriculum lessons or assessments to Bloom's Taxonomy; whether they developed their own curriculum, were skilled in developing curricula or had attended professional development activities. The teacher questionnaire was subjugated to review by academics in a College of Education of the only public university. The revisions attempted to obtain a level of construct validity based on adequateness and appropriateness. The revisions went through a second review by the authors and incorporated into the instruments.

\subsection{Interview Questionnaire}

The authors developed semi-structured interviews questions that asked teachers how the curriculum was developed. In addition, teachers were asked what they perceived as the greatest challenges in their abilities to address the curriculum standards in the preparation of the curriculum and assessment. The questions received face validity from specialist in the field. The specialist were faculty members teaching a methods courses to in-service teachers and had knowledge of the standards, curriculum and teacher education programs. The College of Education is the only college in Qatar that prepares teachers professionally and faculty at the College had the critical and specialist knowledge.

\subsection{Rating of the Alignment of Curriculum-Standard}

Experts in the area rated the curriculum material based on 9 criteria listed below, the rating was performed on the nine criteria for each subject area: Arabic, English, mathematics and science. To validate the rating along the nine criteria. For each subject area, two raters were recruited to judge the curriculum material along the nine criteria. The inter-rater reliability came to 0.85 . The two raters rated the curriculum material on a 4-point scale. The scale extended from zero (inappropriate or missing) to three (entirely appropriate, high quality). A mid-point on the scale would come to about 2.5 .

The nine criteria were:

(1) Standards Number-Was the number of identified appropriate for the designated unit or lesson?

(2) Standard Grouping-Was the grouping of the standards natural and appropriate for the subject and activities?

(3) Standards Level-Were the standards appropriate for the age level/grade level of the students?

(4) Content Objectives-Were the objectives aligned with the standards according to content?

(5) Objective Level-Was the cognitive level of the objectives the same as that required in the standard (Bloom's level)?

(6) Content Activities-Did the activities specifically address the knowledge and skills targeted in the standards?

(7) Activity Level-Were the activities appropriate for students of the age and grade level identified in the standards?

(8) Content Assessment-Did the assessment specifically address the knowledge and skills targeted in the standards?

(9) Assessment Level-Were students assessed at the cognitive level targeted in the standards? 


\subsection{Data Collection}

The nine selected schools were contacted and asked to provide copies of all teacher-developed fourth grade curriculum materials in the four subject areas: Arabic, English, mathematics and science. Grade 4 was selected because it is a transitional stage between lower and upper primary grade. In grade three and below, a single teacher or "home teacher" attends to most subjects. Whereas, in grade 4, there are subject teachers. All nine schools provided the mathematics and English curriculum, seven submitted the Arabic curriculum, and five schools contributed to the science curriculum.

Fifty-eight teachers were administered the questionnaire and 28 fourth grade teachers of the first cohort schools (fourth-grade Arabic, English, mathematics and science teachers in the nine schools) were interviewed. Two graduate students who had been trained in interview procedures and protocols conducted the interviews.

\section{Data Analysis and Findings}

\subsection{Survey Questionnaire Results}

The results indicated that teachers had made substantial effort to align materials to standards and effective teaching. We considered that the midpoint on the rating scale as the theoretical population mean; thus, we compared teacher ratings to the midpoint to determine any significant deviation from the theoretical mean (to see each item means and significance refer to Table 1).

Teachers rated negatively the following items: design of units, knowing Qatar's national curriculum standards, using Bloom's taxonomy in planning lessons, using and finding resources. In terms of lesson assessment, none of the items were significantly different than the ideal mean. More interesting, teachers preferred to work in teams and did so frequently. It was also clear that schools and teachers put a high priority on standards alignment, on studying the standards and on using standards consistently in planning (Table 1).

Table 1. Teacher alignment self-rating scale

\begin{tabular}{lllll}
\hline Item & Mean & $\begin{array}{l}\text { Std. } \\
\text { Dev. }\end{array}$ & t-test & p-value \\
\hline I design my own lesson plans. & 2.48 & .78 & -.178 & .86 \\
I design my own units. & 2.08 & 1.07 & -2.80 & .01 \\
I design my own assessments. & 2.37 & .91 & -.99 & .33 \\
I work alone to design curriculum. & 1.02 & 1.16 & -8.90 & .00 \\
I work with a team to design curriculum. & 1.91 & 1.01 & -3.95 & .00 \\
I know the NQCS very well. & 2.04 & 1.04 & -3.17 & .00 \\
I do not like to design lessons. & .44 & .75 & -19.74 & .00 \\
I do not like working in a team. & .27 & .66 & -24.37 & .00 \\
I find the NQCS confusing. & 1.16 & .99 & -9.49 & .00 \\
I make modifications for my special needs students when I plan lessons. & 1.88 & .79 & -5.58 & .00 \\
I make modifications for my special needs students & when & & \\
assessments. & 1.83 & .89 & -5.52 & .00 \\
I use Bloom's taxonomy in planning lessons. & 2.06 & .99 & -3.11 & .00 \\
I use a textbook to help me plan lessons. & 2.04 & .82 & -4.08 & .00 \\
I use the textbook during lessons. & 1.94 & .99 & -4.04 & .00 \\
I use the Internet to help me plan lessons. & 2.08 & .93 & -3.30 & .00 \\
I find it hard to find resources for my lessons. & 0.85 & 1.09 & -10.93 & .00 \\
I start planning for lessons by selecting the standards. & 2.43 & .87 & -.58 & .57 \\
I use group work in my lessons. & 2.40 & .80 & -.87 & .39 \\
I use hands-on activities in my lessons. & 2.50 & 1.71 & .000 & 1.0 \\
I read and study the standards. & 2.37 & .86 & -1.12 & .27 \\
\hline
\end{tabular}


I enjoy developing my own curriculum.

I feel skillful in developing curriculum.

I worry about the quality of the lessons I design.

I check to ensure that my lessons are aligned with the standards.

I check to ensure that my assessments are aligned with the standards.

I have a peer or coordinator who checks my planned lessons to see if they are aligned with standards before I teach them.

There are resources that I use to check my planned assessments to see if they are aligned with standards before I give them.

My school provides professional development in standards alignment.

I attend professional development in standards alignment given by the SEC.

We discuss standards at our school.

\begin{tabular}{llll}
2.25 & .97 & -1.86 & .07 \\
2.02 & 1.02 & -3.40 & .00 \\
1.78 & 1.01 & -5.08 & .00 \\
2.54 & .79 & .36 & .72 \\
2.49 & .76 & -.09 & .93 \\
2.58 & .85 & .65 & .52 \\
2.31 & .83 & -1.67 & .10 \\
2.31 & .98 & -1.41 & .16 \\
1.79 & 1.14 & -4.49 & .00 \\
2.37 & .91 & -1.07 & .29 \\
\hline
\end{tabular}

NQCS $=$ National Qatar Curriculum Standards.

\subsection{Rating of the Alignment of Curriculum-Standard}

Four judges rated the curriculum material. Each judge rated the material from nine schools for each subject. The subject area specialist entered the ratings into frequency tables and the mean for each factor was determined for the four subject areas: Arabic, English, math and science. Tables 2, 3, 4 and 5 present the means for each subject area for all schools respectively. Each of the tables used the following codes for the nine criteria.

$S-N=\quad$ number of standards

$S-G=\quad$ grouping of standards

$S-L=\quad$ developmental level of standards

$O-C=$ content of objectives

$O-L=\quad$ cognitive level of objectives

$A C-C=$ content of activities

$A C-L=$ developmental level of activities

$A S-C=$ content of assessments

$A S-L=$ cognitive level of assessments

Ratings above the mean value of 1.5 were considered to be strongly aligned. It is clear from the data that in all subject areas, teachers did not find selecting standards problematic. Identifying appropriate numbers of standards, grouping them in appropriate sets and selecting appropriate grade level for standards were also strongly aligned. Teachers were far less successful in writing specific lesson objectives that aligned with those standards, except in mathematics lessons. In Arabic language, teachers were rated less successfully in alignment matching the objective to the standard content. In all subjects but mathematics, the objectives were rated below the mid-point for cognitive level (according to Bloom's taxonomy) than was stated in the standard or the required demonstration of knowledge or skills was below the mid-point. The most noticeable area of misalignment was in content and cognitive level of assessment compared to the rest of the criteria. 
Table 2. Means by school in Arabic language for each criterion

\begin{tabular}{llllllllll}
\hline & S-N & S-G & S-L & O-C & O-L & AC-C & AC-L & AS-C & AS-L \\
\hline Sch1 & 2.73 & 2.27 & 2.91 & 2.64 & 2.73 & 2.09 & 2.09 & 0.55 & 0.55 \\
Sch2 & 1.08 & 1.08 & 2.38 & 0.31 & 0.15 & 1.38 & 1.46 & 0.38 & 0.38 \\
Sch3 & 2.34 & 0.68 & 2.16 & 1.58 & 1.64 & 1.48 & 1.42 & 0.66 & 0.62 \\
Sch4 & 2.78 & 0.22 & 2.91 & 2.13 & 2.22 & 1.57 & 1.48 & 1.26 & 1.30 \\
Sch5 & 2.38 & 0.42 & 2.27 & 1.19 & 1.23 & 1.19 & 1.23 & 0.81 & 0.80 \\
Sch6 & 2.31 & 2.30 & 2.27 & 0.38 & 0.45 & 1.28 & 1.42 & 0.46 & 0.45 \\
Sch7 & 1.20 & 1.20 & 1.80 & 1.60 & 1.40 & 1.80 & 1.80 & 1.00 & 1.20 \\
\hline Mean & 2.12 & 1.17 & 2.39 & 1.40 & 1.40 & 1.54 & 1.56 & 0.73 & 0.76 \\
\hline
\end{tabular}

Table 3. Means by school in English language for each criterion

\begin{tabular}{llllllllll}
\hline & S-N & S-G & S-L & O-C & O-L & AC-C & AC-L & AS-C & AS-L \\
\hline Sch1 & 2.80 & 2.88 & 2.88 & 2.70 & 2.68 & 1.38 & 1.33 & 1.28 & 1.28 \\
Sch2 & 2.97 & 2.78 & 2.06 & 2.00 & 1.42 & 1.64 & 1.53 & 1.86 & 0.97 \\
Sch3 & 3.00 & 3.00 & 3.00 & 1.97 & 1.97 & 1.93 & 2.00 & 1.27 & 1.47 \\
Sch4 & 3.00 & 2.92 & 2.92 & 1.92 & 1.77 & 1.77 & 1.69 & 0.69 & 0.69 \\
Sch5 & 1.47 & 1.89 & 2.53 & 1.79 & 1.84 & 1.89 & 1.84 & 1.26 & 1.26 \\
Sch6 & 2.00 & 2.00 & 1.10 & 1.25 & 1.15 & 1.15 & 1.20 & 1.10 & 0.90 \\
Sch7 & 0.99 & 1.03 & 1.03 & 0.72 & 0.72 & 1.57 & 1.57 & 1.57 & 1.55 \\
Sch8 & 2.88 & 2.88 & 2.88 & 2.88 & 2.63 & 1.88 & 1.75 & 1.00 & 1.00 \\
Sch9 & 2.97 & 2.97 & 2.97 & 1.97 & 1.93 & 1.62 & 1.62 & 1.14 & 1.10 \\
\hline Mean & 2.45 & 2.48 & 2.37 & 1.91 & 1.79 & 1.65 & 1.61 & 1.24 & 1.14 \\
\hline
\end{tabular}

Table 4. Means by School for mathematics

\begin{tabular}{llllllllll}
\hline & S-N & S-G & S-L & O-C & O-L & AC-C & AC-L & AS-C & AS-L \\
\hline Sch1 & 3.00 & 3.00 & 2.55 & 3.00 & 2.95 & 2.80 & 2.95 & 2.70 & 2.55 \\
Sch2 & 3.00 & 3.00 & 2.94 & 3.00 & 3.00 & 3.00 & 3.00 & 3.00 & 2.75 \\
Sch3 & 2.70 & 3.00 & 2.85 & 3.00 & 3.00 & 3.00 & 3.00 & 3.00 & 2.88 \\
Sch4 & 2.94 & 2.93 & 3.00 & 2.94 & 2.85 & 2.85 & 2.85 & 2.85 & 2.85 \\
Sch5 & 2.85 & 2.85 & 3.00 & 2.85 & 2.78 & 2.83 & 2.85 & 2.43 & 2.85 \\
Sch6 & 3.00 & 3.00 & 2.95 & 3.00 & 2.57 & 2.57 & 2.43 & 2.43 & 2.14 \\
Sch7 & 2.57 & 2.55 & 2.88 & 2.58 & 2.43 & 2.53 & 2.32 & 2.30 & 2.37 \\
Sch8 & 2.41 & 2.41 & 3.00 & 2.41 & 2.16 & 2.35 & 2.40 & 2.41 & 1.95 \\
Sch9 & 2.77 & 2.77 & 3.00 & 2.77 & 2.36 & 2.43 & 2.71 & 2.71 & 2.71 \\
Mean & 2.80 & 2.83 & 2.91 & 2.84 & 2.68 & 2.71 & 2.72 & 2.65 & 2.56 \\
\hline
\end{tabular}


Table 5. Means by school in science for each criterion

\begin{tabular}{llllllllll}
\hline & S-N & S-G & S-L & O-C & O-L & AC-C & AC-L & AS-C & AS-L \\
\hline Sch1 & 1.98 & 2.08 & 2.05 & 2.63 & 2.63 & 1.13 & 1.03 & 0.93 & 0.93 \\
Sch2 & 2.64 & 2.82 & 3.00 & 2.91 & 2.91 & 3.00 & 3.00 & 2.45 & 2.55 \\
Sch3 & 1.82 & 1.82 & 1.82 & 2.82 & 2.82 & 1.68 & 1.68 & 1.68 & 1.68 \\
Sch4 & 1.85 & 2.15 & 2.08 & 2.15 & 2.15 & 0.62 & 0.31 & 0.00 & 0.00 \\
Sch5 & 2.33 & 2.67 & 3.00 & 2.83 & 2.83 & 3.00 & 3.00 & 2.67 & 2.83 \\
Mean & 2.12 & 2.31 & 2.39 & 2.67 & 2.67 & 1.89 & 1.80 & 1.55 & 1.60 \\
\hline
\end{tabular}

We also ran a repeated measure ANOVA to determine whether there were any differences between the select schools. The set-up of the ANOVA was within school and between the nine criteria. In Arabic language, none of the seven schools scored satisfactory across all criteria. The lowest scores appeared on identifying the number of standards in a group and content assessment aligned to the curriculum standards (see Table 1). Only one school scored satisfactory on two criteria: the number of standards and the grouping of standards with means at the satisfactory level. Alignment of five of the standard factor grouping, objectives, cognitive level of the standard, content assessment and cognitive level of assessments-were rated below the satisfactory level. The difference between schools was significant as reported by Greenouse-Geisser $F(8,64)=5.89, p=0.01$. We used Greenhouse Geisser because the assumption of homogeneity was rejected suggesting that there is an unequal differences in the rating across the schools.

In English language assessment of content and cognitive level of assessment, the analysis showed below satisfactory level ratings. Greenouse-Geisser repeated measure ANOVA showed significant differences between school ratings (within the repeated measure) $F(8,64)=11.07, p=0.001$. The repeated measures ANOVA showed differences between the schools on the nine criteria.

The data related to mathematics clearly did not match the other sets (Table 4). Judges rated satisfactory on all the criteria across all schools, expert or above. Clearly mathematics curriculum, with its quantitative focus, was straightforward to align; however, significant differences appeared between each school on the rated criteria with Greenhouse Geisser $\mathrm{F}(8,64)=11.1, \mathrm{p}=0.000$.

Lastly in terms of science curricula, schools varied greatly in degree of alignment (Table 3). All schools had means in the satisfactory range, with alignment of objectives approaching target levels. Again the large variances between schools had shown a large difference of Greenouse-Geisser $F(8,64)=3.923, p=0.02$ (within the repeated measure).

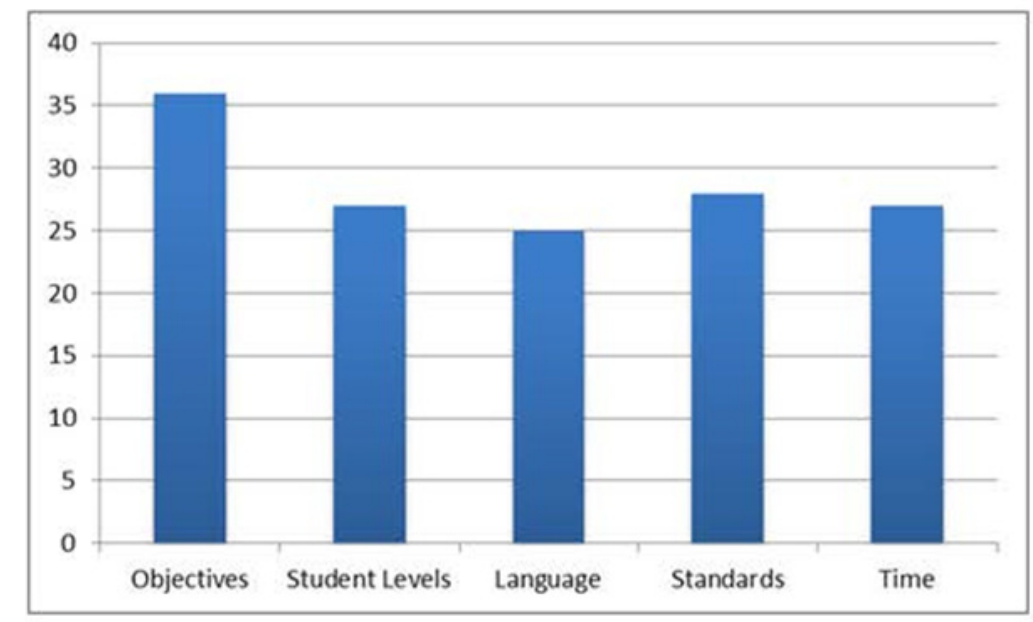

Figure 1. Number of times topics were introduced by the participants during interviews 


\subsection{Interviews}

The interviews allowed for an in depth understanding of the perceptions related to curriculum development. The main themes that arose out of the interview were the difficulty in selecting objectives and standards (Figure 1). Teachers also felt they knew a great deal about standards, but were less confident in writing objectives based on those standards. Another major issue revealed the difficulty of matching standards written to the actual level of the students. As a number of teachers said: "How can we write an objective that matches the standard in addition to the ability level of the students, especially with the language issue?" This teacher was referring to students' language abilities in English. It was very difficult for the students to understand the language i.e., English, in which these objectives were written.

Another major concern was the time factor: The perception among teachers was that their extensive workload could not be fulfilled in the allotted time frame. As teachers repeatedly said, there was "...too much curriculum and too many standards." Many teachers felt that in face of the changes in their schools specifically in the transformation to a standard-based curriculum, they were overburdened by being required to develop curriculum, lesson plans and assessments and at the same time being required to adopt new pedagogical strategies.

\section{Discussion}

The findings in this study have local and general implications. Teachers in this context are given significant roles in developing and aligning curriculum to standards without having the skill, professional development or time to do so effectively. As mentioned by Davis-Becker and Buckendahl (2013), developing and aligning standards requires a great deal of professional development and experience. These teachers were at the same time being faced with new teaching methods and learning how to deal with standards. As there were also significant differences in the ratings between schools and thus differences between teachers in different schools, one suggestion would be to provide opportunity for teachers exhibiting commendable skill to provide capacity to other teachers.

The study also found that in three subject areas-Arabic, English and science-the teacher-developed curriculum was not closely aligned with the standards upon which student achievement could be determined. This may have contributed to the under achievement of students on the national tests that are linked to the standards. The research further questions the decision to require teachers to develop curriculum materials in schools, especially schools in this context which have major issues related to the language of instruction; however, it should be noted that serious misalignment was shown by teachers of Arabic, even though the language of instruction was not an issue. This may be because Arabic standards were the last subject to have curriculum standard developed (year 2008), and teachers have received little professional development work on alignment. Further professional development in alignment techniques and method could result in higher levels of alignment. Based on the three sources of data, the following recommendations are made:

(1) It may be advisable to reconsider the decision to have the majority of curriculum developed at the teacher level.

(2) If teachers are to develop content, they need more professional development on how to develop curriculum, to select and evaluate content and to design assessments that are aligned to standards.

(3) More studies should be conducted to check the effect of using the English language as a medium of instruction on teaching science and mathematics.

(4) More studies should be conducted on the effects of requiring teachers to develop curriculum.

(5) A review of the curriculum standards to check whether they suit student level of proficiency and needs may be needed.

It was clear from all sources of data, that schools and individual teachers are making a sincere, dedicated and focused effort to address standards in curriculum development; however, this effort needs more support if it is to appropriately meet the needs of students in this challenging educational context. A recent development, after the end of the study, the Supreme Education Council reached conclusions to eliminate all teacher developed curriculum development and assessments. Teachers now have school textbooks aligned with standards and developed specifically for the Qatari standards. The degree of alignment in these texts would be an appropriate further research question.

\section{References}

Al-Sulayti, H. (1999). Education and Training in GCC Countries: Some Issues of Concern. Education and the Arab World: Challenges for the Next Millennium. Abu Dhabi, UAE: The Emirates Centre for Strategic 
Studies and Research.

Baker, E. (2004). Aligning curriculum, standards, and assessments: Fulfilling the promise of school reform. Los Angeles, CA: National Center for Research on Evaluation, Standards, and Student Testing (CRESST) University of California. Retrieved May 7, 2008, from http://www.eric.ed.gov/ERICDocs/data/ericdocs2sq1/ content_storage_01/0000019b/80/1b/9e/2b.pdf

Bhola, D. S., Impara, J. C., \& Buckendahl, C. W. (2003). Aligning tests with states' content standards: Methods and issues. Educational Measurement: Issues and Practice, 22, 21-29. http://dx.doi.org/10.1111/j.1745-3992.2003.tb00134.x

Bloom B. S. (1956). Taxonomy of educational objectives, handbook I: The cognitive domain. New York: David McKay Co. Inc.

Brewer, D., Augustine, C., Zellman, G., Ryan, G., Goldman, C., Stasz, C., \& Constant, L. (2007). Education for a new era: Design and implementation of K-12 education reform in Qatar. Rand Corporation. Retrieved November 12, 2007, from http://www.rand.org/pubs/monographs/2007/RAND_MG548.pdf

Contino, J. (2013). A Case Study of the Alignment between Curriculum and Assessment in the New York State Earth Science Standards-Based System. Journal of Science Education and Technology, 22(1), 62-72. http://dx.doi.org/10.1007/s10956-012-9376-x

Davis-Becker, S., L., \& Buckendahl, C. (2013). A Proposed Framework for Evaluating alignment Studies. Educational Measurement: Issues and Practice, 32(1), 23-33. http://dx.doi.org/10.1111/emip.12002

Education Institute. (2005). Curriculum standards for the state of Qatar. Doha, Qatar: Supreme Education Council.

Fulmer, G. (2011). Assessments, and instruction estimating critical values for strength of alignment among curriculum. Journal of Educational and Behavioral Statistics, 36, 381-402. http://dx.doi.org/10.3102/1076998610381397

Gannod, B., Gannod, G., \& Henderson, M. (2005). Course, program, and curriculum gaps: Assessing curricula for targeted change. 35th ASEE/IEEE Frontiers in Education Conference. Indianapolis, IN. October 19-25, 2005. Retrieved May 7, 2008, from http://ieeexplore.iee.org/iel5/10731/33854/01611930.pdf?isnumber $=33854 \&$ prod $=\mathrm{CNF} \&$ arnumber $=1611930 \& \operatorname{arSt}=+\mathrm{T} 3 \mathrm{C}-19 \&$ ared $=+\mathrm{T} 3 \mathrm{C}-24 \&$ arAuthor $=$ Gannod\%2C + B.D. $\% 3 \mathrm{~B}+$ Gannod $\% 2 \mathrm{C}+$ G.C. $\% 3 \mathrm{~B}+$ Henderson $\% 2 \mathrm{C}+\mathrm{M} . \mathrm{R}$.

Herman, J., \& Webb N. M., (2007). Alignment Methodologies, Applied Measurement in Education. Applied Measurement in Education, 20(1), 1-5. http://dx.doi.org/10.1080/08957340709336727

Herman, J. L., Webb, N. M., \& Zuniga, S. A. (2007). Measurement Issues in the Alignment of Standards and Assessments: A Case Study. Applied Measurement In Education, 20(1), 101-126.

Lincoln, Y., \& Guba, E. (1985). Naturalistic inquiry. Beverly Hills CA: Sage Publications.

National Commission on Excellence in Education. (1983). A nation at risk: Imperative for education reform. Washington, DC: Author.

Nunan, D. (2001, May). The latest on language and languages. World News, (51). Retrieved May 7, 2008, from http://www.fiplv.org/news/news51.htm

Plake, B. S., Buckendahl, C. W., \& Impara, J. C. (2001, June). A comparison of publishers' and teachers' perspectives on the alignment of norm-referenced tests to Nebraska's language-arts content standards. Paper presented at the annual large-scale assessment conference of the council of chief state school officers, Snowbird, UT.

Porter, A.C. (2002). Measuring the content of instruction: Uses in research and practice. Educational Researcher, 31(7), 3-14. http://dx.doi.org/10.3102/0013189X031007003

Rothman, R., Slattery, J. B., Vranek, J. L., \& Resnick, L. B. (2002). Benchmarking and alignment of standards and testing (CSE Technical Report 566). Los Angeles: University of California-Los Angeles, Center for the Study of Evaluation, National Center for Research on Evaluation, Standards, and Student Testing.

Sahlberg, P. (2011). Finnish Lessons. New York: Teachers College Press.

US Department of Education. (n.d.). Pursuing excellence: Chapter 2 curriculum. Washington, DC: national Center for Education Statistics. Retrieved May 7, 2008, from http://nces.ed.gov/pubs97/timss/97198-5.asp

Webb, N. L. (2007). Issues Related to Judging the Alignment of Curriculum Standards and Assessments. Applied 
Measurement in Education, 20(1), 7-25. http://dx.doi.org/10.1080/08957340709336728

Webb, N. L. (1999). Alignment of science and mathematics standards and assessments in four states (Research Monograph No. 18.). Madison, WI: University of Wisconsin Madison, National Institute for Science Education.

Wixson, K. K., Fisk, M. C., Dutro, E., \& McDaniel, J. (2002). The alignment of state standards and assessments in elementary reading (CIERA Rep. No. 3-024). Ann Arbor: University of Michigan, School of Education, Center for the Improvement of Early Reading Achievement.

Zellman, G. L., Ryan, G. W., Karam, R., Constant, L., Salem, H., Gonzalez, G., . . A Al-Obaidi, K. (2009). Implementation of the K-12 education reform in Qatar's schools. Rand Qatar Policy Institute.

\section{Copyrights}

Copyright for this article is retained by the author(s), with first publication rights granted to the journal.

This is an open-access article distributed under the terms and conditions of the Creative Commons Attribution license (http://creativecommons.org/licenses/by/3.0/). 